\title{
TITLE:
}

\section{On Phenomena Forerunning Earthquakes}

$\operatorname{AUTHOR}(\mathrm{S}):$

SASSA, Kenzo; NISHIMURA, Eiichi

CITATION:

SASSA, Kenzo ...[et al]. On Phenomena Forerunning Earthquakes.

Bulletins - Disaster Prevention Research Institute, Kyoto University 1956, 13: 1-9

ISSUE DATE:

1956-03-05

URL:

http://hdl.handle.net/2433/123665

RIGHT: 


\title{
On Phenomena Forerunning Earthquakes*
}

\author{
By \\ Kenzô Sassa and Eiichi Nishimura
}

\section{Introduction}

Among various natural disasters the damage caused by destructive earthquakes is the most horrible and fatal besause of their great violence and unforeseen occurrence. Recently developed seismology tells us in great detail of various phenomena observed after an instance of earthquake occurrence, such as the location of fosus, total energy of the earthquake, propagation mode of the seismic wave, safety factors in building and construction against earthquakes, and others. But, much to our regret, we have no definite knowledge concerning the period just before an earthquake-occurrence. The study of the phenomena foretelling the occurrence of destructive earthquakes is considered to be one of important items in both the practical and basic aspects of seismology, because an early warning against a coming destructive earthquake would considerably reduce much disastrous loss, especially that of human life, and furthermore, the knowledge about the phenomena forerunning earthquakes would serve greatly towards the solution as to the real nature of earthquakes, namely the process of the accumulation of earthquake energy, the mode of its release, the triggering action for its release, and others.

Among the various phenomena observed in the epicentral region after the occurrence of destructive earthquakes, the upheaval of the ground is the most conspicuous. And it has also been observed by the repetition of precise levelling that this sort of ground movement in some cases precedes the occurrence of earthquakes. In these cases the continuous observation of the ground movement with suitable instruments would certainly serve the purpose of foretelling earthquake-occurrence.

Along this line some observations with tiltmeters, extensometers and other instrument have been made, since 1937, at several stations in Japan under the

*The paper was read at the Tenth General Assembly of the International Union of Geodesy and Geophysics held in Rome, September, 1954. 
management of our Institute. At present forty tiltmeters, twenty extensometers, ten geomagnetic declinometers and five gravimeters are set up at the following fifteen stations. [Ref. 1]

\begin{tabular}{l|l|l|l|l}
\hline & longitude & latitude & Rock formation & $\begin{array}{l}\text { Room depth below } \\
\text { t'ie ground surface }\end{array}$ \\
\hline Makimine & $131^{\circ} 27^{\prime} \mathrm{E}$, & $32^{\circ} 37^{\prime} \mathrm{N}$, & Paleozoic state & $180 \mathrm{~m}, 165 \mathrm{~m}$ \\
Hondo & $131^{\circ} 05^{\prime} \mathrm{E}$, & $32^{\circ} 53^{\prime} \mathrm{N}$, & Volcanic rock & 1 \\
Kochi & $131^{\circ} 32^{\prime} \mathrm{E}$, & $33^{\circ} 34^{\prime} \mathrm{N}$, & Paleozoic & 40 \\
Ikuno & $134^{\circ} 50^{\prime} \mathrm{E}$, & $35^{\circ} 10^{\prime} \mathrm{N}$, & Liparte & $719,326,237$ \\
Susami & $135^{\circ} 30^{\prime} \mathrm{E}$, & $33^{\circ} 32^{\prime} \mathrm{N}$, & Paleozoic & 10 \\
Kishyu & $135^{\circ} 53^{\prime} \mathrm{E}$, & $33^{\circ} 52^{\prime} \mathrm{N}$, & Tertiary sandstone & 60 \\
Yura & $135^{\circ} 07^{\prime} \mathrm{E}$, & $33^{\circ} 57^{\prime} \mathrm{N}$, & Mesozoic sandstone & 30 \\
Ide & $135^{\circ} 49^{\prime} \mathrm{E}$, & $34^{\circ} 48^{\prime} \mathrm{N}$, & and shale & 35 \\
Abuyama & $135^{\circ} 34^{\prime} \mathrm{E}$, & $34^{\circ} 52^{\prime} \mathrm{N}$, & Paleozoic & 20 \\
Osakayama & $135^{\circ} 51^{\prime} \mathrm{E}$, & $34^{\circ} 59^{\prime} \mathrm{N}$, & Paleozoic & 150 \\
Kamigamo & $135^{\circ} 46^{\prime} \mathrm{E}$, & $35^{\circ} 04^{\prime} \mathrm{N}$, & Paleozoic & 10,9 \\
Tsuchikura & $136^{\circ} 18^{\prime} \mathrm{E}$, & $35^{\circ} 36^{\prime} \mathrm{N}$, & Paleozoic & 170 \\
Ogoya & $136^{\circ} 33^{\prime} \mathrm{E}$, & $36^{\circ} 17^{\prime} \mathrm{N}$, & Tertiary tuff & $300,300,200$ \\
Kamioka & $137^{\circ} 19^{\prime} \mathrm{E}$, & $36^{\circ} 21^{\prime} \mathrm{N}$, & Gneiss & 800 \\
Hosokura & $140^{\circ} 54^{\prime} \mathrm{E}$, & $38^{\circ} 48^{\prime} \mathrm{N}$, & Tertiary & 160 \\
\hline
\end{tabular}

In the following detailed descriptions will be made of some peculiar changes of ground-tilt and ground-strain intimately related to the recent occurrence of some destructive earthquakes in Japan.

\section{Changes within several hours}

Some examples of a peculiar change of ground-tilt observed within a period of several hours just before the occurrence of destructive earthquakes are described in the following:

On September 10, 1943, a destructive earthquake occurred in the vicinity of Tottori City; there were 7348 casualities and 13,897 buildings were damaged. The position of epicenter was $134^{\circ} .2 \mathrm{E}$ and $35^{\circ} .5 \mathrm{~N}$, the depth of focus and seismic magnitude being $10 \mathrm{~km}$ and 7.5 in Pasadena Scale respectively. Our nearest observation station to the epicenter $(\Delta=60 \mathrm{~km})$ was Ikuno Station, and there a minute but clear and characteristic tilting motion of the ground was 


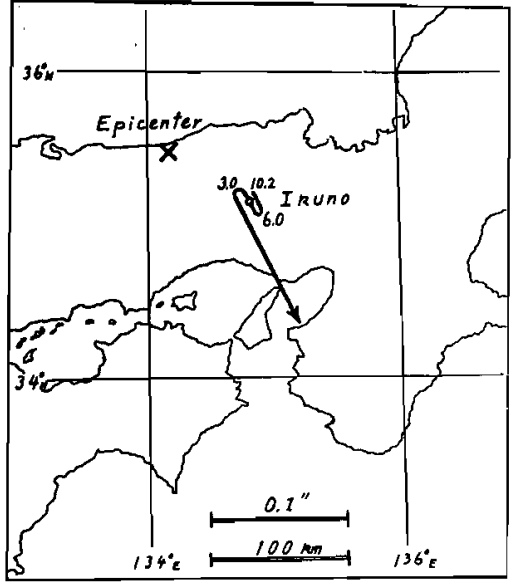

Fig. 1 Tilting motion of ground observed at Ikuno before the occurrence of the Tottori Earthquake on September $10,194.3$. observed several hours before the occurrence of the Tottori Earthquake. In Figure 1, this peculiar ground-tilt is schematically expressed, the direction of the arrowed line showing the direction of the downward tilting motion of the ground and its length representing the amount of tilt. The annexed numerals denote the time in hours counted back from the instant of eartuhqake occurrence. Although the amount of this forerunning tilting motion is minute, its S-type motion is very peculiar and clearly distinguishable from the other usual tilting motions. [Ref. 2, Ref. 3]

On December 7, 1944, the great

Tônankai Earthquake occurred at a point $20 \mathrm{~km}$ offshore in the open sea of Kumano-Nada; there were 3133 casualities and 76,151 buildings were damaged, mainly by a tsunami reaching several meters in height. The epicenter, focal depth and seismic magnitude were estimated to be $136 .{ }^{\circ} \mathrm{E}$ and $33 . .^{\circ} 7 \mathrm{~N}$, about $20 \mathrm{~km}$ and 8.0 in Pasadena Scale respectively. In this case the only observation anywhere near the epicenter was Kamigamo Geophysical Observatory, $160 \mathrm{~km}$ distant in the northern part of Kyoto Cíty. In this case also, an extremely minute but clear ground-tilt was observed at Kamigamo, the schematic diagram being expressed in Figure 2. [Ref. 3]

On April 26, 1950, the strong Nanki Earthquake occurred in the southern part of Kii Peninsula. The epicenter, focal depth and seismic magnitude were $135 .{ }^{\circ} 8$ $E$ and $33 . .^{\circ} 9 \mathrm{~N}, 40 \mathrm{~km}$, and 6.7 in Pasadena Scale respectively, but the damage was small. In this case, the tiltgrams

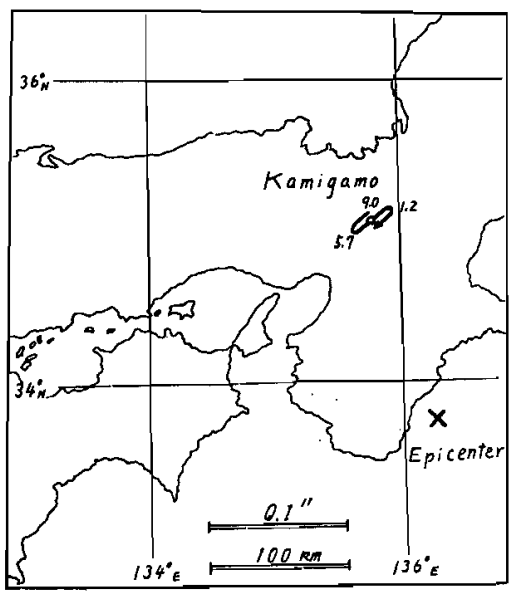

Fig. 2 Tilting motion of ground observed at Kamigamo before the occurrence of the Tónankai Earthquake on December 7, 1944. 


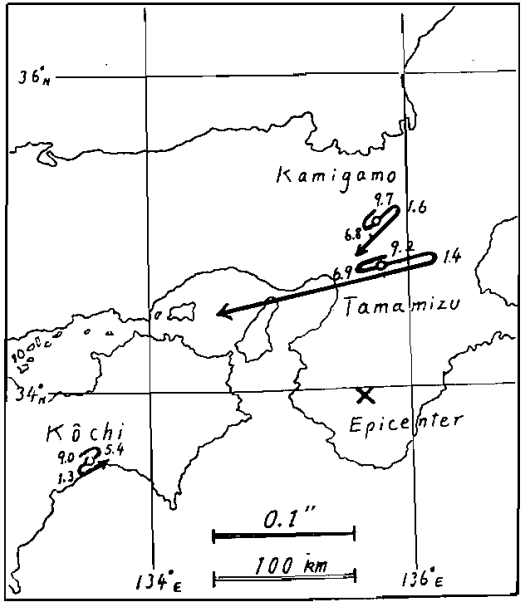

Fig. 3 Tilting motions of ground observ. ed at Tamamizu, Kamigamo and Kochi hefore the occurrence of the Nanki Earthquake on April 26, 1950. obtained at Tamamizu Station (at present in suspension), Kamigamo Geophysical Observatory and Kôchi Station showed the peculiar S-type ground-tilt several hours before the occurrence of the Nanki Earthquake. The Tamamizu, Kamigamo and Kôchi Stations were respectively $80 \mathrm{~km}, 120 \mathrm{~km}$ and $200 \mathrm{~km}$ distant from the epicenter as in Fig. 3 [Ref. 3]

Comparing Figures 1,2 and 3 with each other, it is concluded that a great or destructive eathquake is in some cases (at least in the present cases) preceded by a minute and characteristic S-type tilting motion of the ground several hours before its occurrence. Roughly speaking, observed tilts were of the order of magnitude of $0^{\prime \prime} .1$ in angle at a distance of $100 \mathrm{~km}$ from the epicenter.

\section{Changes in several days and several months}

The above described changes observed several hours before the earthquakeoccurrence are considered to be very important and suggestive for the research as to the nature of earthquakes, but it is practically very difficult to make them sorviceable for the early warning of earthquake-occurrence because of its imminence in time. For the purpose of warning against the occurrence of a destructive earthquake and reducing disastrous loss, it is desirable to catch any phenomena foretelling the disaster which should appear at a sufficient interval before the earthquake-occurrence. But the accurate observation of secular change in ground-tilt and ground-strain is a considerably difficult task, because of the amount of change sought is generally very minute compared with the irrelevant disturbances caused by ground movements of local character, meteorological effects, instrumental defects and artificial interruptions. [Ref. 4] In spite of these diffculties two cases were recently observed, in which slow and peculiar ground-tilt and ground-strain appeared several months before earthquake-occurrence, and the rapid and severe change were observed several days before the instant of occur- 
rence. Their circumstances may be reported in some detail.

\section{(a) The Gase of Daishoji-Oki Earthquake}

The strong Daishôji-Oki Earthquake of March 7, 1952 had its epicenter, $40 \mathrm{~km}$ distant from Ogoya Station in the NW-direction. Its epicenter, focal depth and seismic magnitude were $136.2 \mathrm{E}$ and $36 . .^{\circ} \mathrm{N}, 20 \mathrm{~km}$ and 6.5 in Pasadena Scale respectively. The secular change of ground-tilt observed is shown in Figure 4 as a vector diagram, in which the direction and amount of change of downward ground-tilt are successively plotted in a vector-representation and the annexed numerals denote the date of observation. As seen in the Figure, the ground at Ogoya, after the commencement of tiltmetric observation on September 23, 1951, had continued its downward tilting in the NW direction until December 5 , and since that date turned its tilting direction to NW. And since

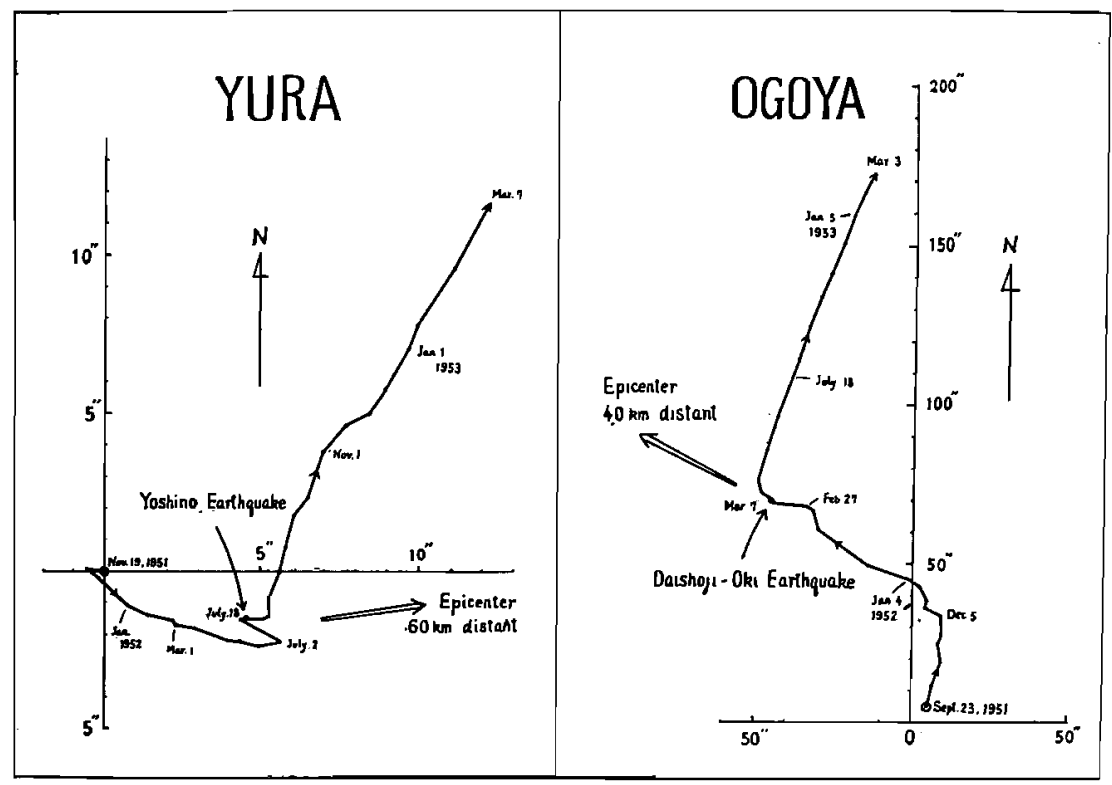

Fig. 4 Vector diagrams of secular change of ground-tilt observed at Yura and Ogoya. Single arrows show the time of oscurrence of earthquake and double arrows the direction of epicenter respectively.

February 27, 1952 the westward tilting motion became more and more severe and continued to the day of the catastrophic Daishôji-Oki Earthquake occurrence of March 7. Several days after earthquake-occurrence the tilting motion of the ground turned its direction to NE, orthogonal to the preceding, and the ground has continued its tilting motion in the same direction (NE) up to the present. 
Namely the ground at Ogoya commenced its downward tilting motion' in the direction of the epicenter three months before the earthquake-pccurrence, increasing its speed of motion several days before the catastrophe, and then several days after earthquake-occurrence turned its direction for the orthogonal to the preceding. [Ref. $4,5,6]$

\section{(b) The Case of the Yoshino-Earthquake}

The strong Yoshino Earthquake of July 18, 1952 has its epicenter $55 \mathrm{~km}$, $72 \mathrm{~km}$ and $94 \mathrm{~km}$ distant respectively from the Yura, Ide, and Osakayama Stations as seen in Figure 5. Its epicenter, focal depth and seismic magnitnde were $135 . .^{\circ} 40 \mathrm{E}$ and $34 .^{\circ} 10 \mathrm{~N}, 70 \mathrm{~km}$ deep and 7.0 Pasadena Scale respectively. As to the tiltmetric observation at Yura, the schematic vector diagram of groundtilt is shown in Figure 6 as in the case of the Daishôji-Oki Earthquake. In this case also the downward tilting motion of the ground at Yura had been towards the ESE direction (the epicenter of the Yoshino Earthquake being in the ENE

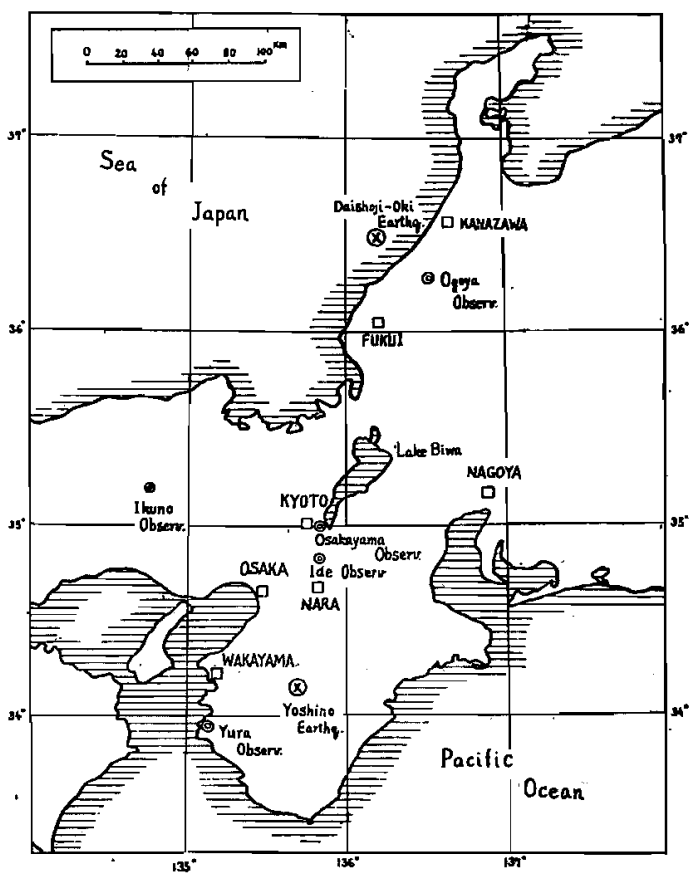

Fig. 5 Positions of the Observatories and epicenters of the Daishoji-Oki and Yoshino Earthquakes: direction from Yura) until

July 2, then turning to the WNW until July 16. And after two days of its reverse motion to $\mathrm{E}$ on July 16, the strong Yoshino Earthquake have occured. After the occurrence the eastward tilting motion continued to July 30 , and the succeeding ground-tilt in the NE-direction continued to September, 1953. Roughly speaking the downward tilting motion of ground at Yura was towards the direction of the epicenter during several months before the earthquake-occurrence, reversing its tilting direction sixteen days before the occurrence, and from twelve 
days after the occurrence the tilting direction has been nearly orthogonal to that of preceding epoch. Thus the modes of secular tilting motion of the ground related to the occurrence of destructive earthquakes are very similar with one another in both cases of Ogoya and Yura. [Ref. 6]

In the case of the Yoshino Earthquake some remarkable changes of groundstrain were observed several months before the earthquake-occurrence in the extensometric observation at the Ide and Osakayama Stations. [Ref. 7, Ref. 8] The extensometric observation at Osakayama Station was commenced early in 1949, and several reports on the relation between the change of ground-strain and earthquake-occurrence has been published. [Ref. 9] In the case of the Yoshino Earthquake, as seen in Figure 6, the gradual extension of the 'ground had taken place nearly one year before and a rapid extension took place three months before the earthquake-occurrence. Nearly one month after the oscurrence, the ground strain changed its behavior from extension to contraction and recovered the original state in nearly one year. Nearly the same remarkable ground-strain was also observed at the Ide Station. There the extensometric observation for the six directions had continued since 1951 and in the case of the Yoshino Earth-

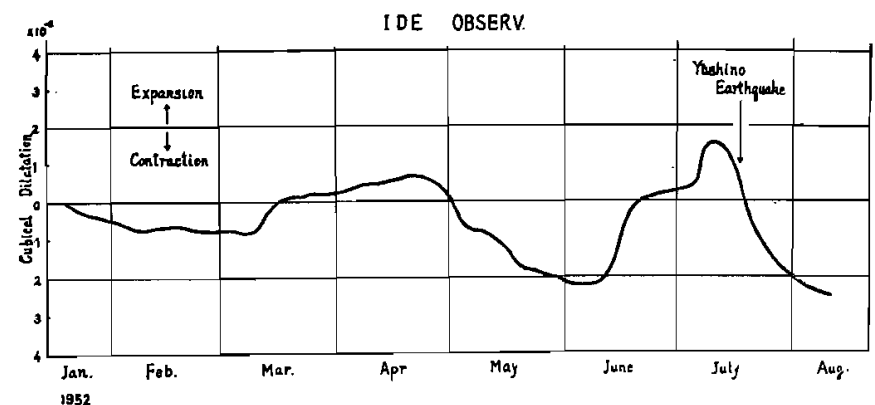

Fig. 7 Secular variation of ground-strain (cubical dilatation) obscrved at Ide Observatory.

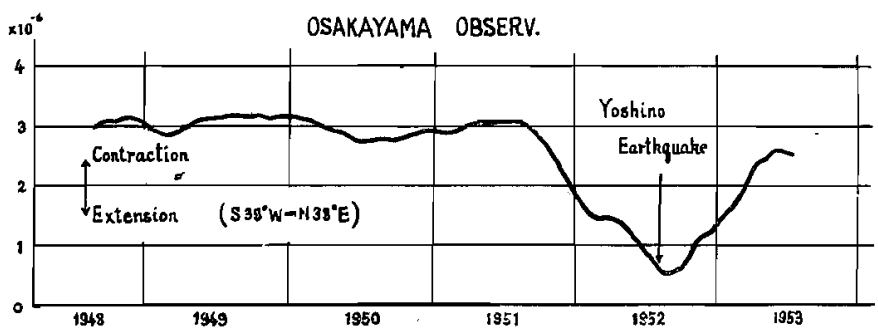

Fig. 6 Secular variation of ground-strain (extension) -observed at Osakayama Observatory. 
quake, some anomalous ground-strains were observed nearly four months and the large ones nearly two months before the occurrence of the earthquake as seen in Fig. 7. In this Figure the anomalous cubical dilatation of ground-strain was shown by the composition of strain components.

In conclusion some anomalous changes of ground-tilt and ground-strain which are considered to precede and be intimately related with the occurrence of destructive earthquakes were reported. It is certainly dangerous to derive any hasty conclusions from such few examples on the phenomena forerunning earthquakeoccurrence, but it is expected that these observed facts may throw some light upon the future development of research in methods of forecasting the earthquake-occurrence and the essential nature of earthquakes.

\section{References}

1) Nishimura, Eiichi : On some destructive earthquakes observed with the tiltmeter at a great distance, Bulletin No. 6, Disaster Prevention Research Institute, Kyoto Univ., Oct. 1953, 1-15.

2) Sassa, Kenzó : Tilting motion of ground observed before and after the destructive Tottori Earthquake, Kagaku (Science), vol. 14, ro. 6, pp. 220-221, 1944 (in Japanese).

3) Sassa, Kenzô and Eiichi Nishimura: On phenomena forerunning earthquakes, Trans. Amer. Geophys. Union, vol. 32, no. 1, pp. 1-6, 1951.

4) Hosoyama, Kennosuke: Characteristic tilt of the ground that preceded the occurrence of the strong earthquake of March 7, 1952, Journ. of Physics of the Earth, vol. 1, no. 2, pp. 75-81, 1952.

5) Nishimura, Eiichi and Kennosuke Hosoyama : On tilting motion of ground observed before and after the occurrence of an earthquake, Trans. Amer. Geophys. Union, vol. 34, no. 4, pp. 597-599, 1953.

6) Hosoyama, Kennosuke: On a mercury tiltmeter and its application, Bulletio No. 6, Disaster Prevention Research Institute, Kyoto Univ., Oct. 1953, pp. 17-25.

7) Sassa, Kenzô, Izuo Ozawa and Sôji Yoshikawa : Observation of tidal strain of the Earth (Part I), Bull. No. 3, Disaster Prevention Research Institute, pp. 1-3, 1952.

8) Ozawa, Izuo: Observation of tidal strain of the Earth by the extensometer (Part II), Bull. No. 3, Disaster Prevention Research Institu:e, pp. 4-17, 1952.

9) Ozawa, Izuo: Observation of ground-strain at Osakayamn-Station, Rep. Disaster Prevention Research Institute, No. 2, Nov. 1949, pp. 115-121 (in Japgnese). 